\title{
Visual Market equilibrium model for power seller multi-microgrid based on a graphic game
}

\section{Modelo visual de equilíbrio de mercado para multi-microrredes exportadoras de energia baseado em um jogo gráfico}

\author{
Henrique Mesquita Tonhá ${ }^{1 *}$, Thyago Carvalho Marques ${ }^{1}$, \\ Bernardo Pinheiro Alvarenga ${ }^{1}$
}

\begin{abstract}
Microgrids (MGs) have characteristics of flexibility and intelligence. These grids provide potential for integrating renewable energy sources. Hybrid Microgrids make possible to manage complementary between sources and storage schemes, enabling exploration of stronger commercial impact of these energy producing stations. This paper proposes a new market model of equilibrium operation for MGs in local energy markets. MGs remotely located in the grid are virtually associated to compete with other MGs better located. The model meets the interests of the MGs by remuneration of the delivered power and the other stakeholders via loss reduction. A deterministic method based on reduction of the constraint set size and application of Karush-Kuhn-Tucker (KKT) conditions process visually the Nash equilibrium (NE) and the Pareto efficiency (PE). The non-cooperative static game has the ability to encourage the participation of small agents in the grid.
\end{abstract}

Keywords: KKT conditions; Local energy markets; Microgrids; Nash equilibrium; Pareto efficiency.

\section{RESUMO}

As microrredes (MRs) possuem características de flexibilidade e inteligência. Essas redes fornecem potencial de integração de fontes de energia renováveis. As microrredes híbridas possibilitam o gerenciamento da complementaridade entre as fontes e os mecanismos de armazenamento, possibilitando a exploração de maior impacto comercial dessas estações produtoras de energia. Este artigo propõe um novo modelo de mercado de operação de equilíbrio para MRs nos mercados locais de energia. MRs localizadas remotamente na rede são virtualmente associadas para competir com outras MRs melhor localizadas. O modelo atende aos interesses das MRs pela remuneração da potência entregue e aos demais stakeholders via redução de perdas. Um método determinístico baseado na redução do tamanho do conjunto de restrições e na aplicação das condições de Karush-Kuhn-Tucker (KKT) processa visualmente o equilíbrio de Nash (EN) e a eficiência de Pareto (EP). O jogo estático não cooperativo tem a capacidade de estimular a participação de pequenos agentes na rede.

Palavras-chave: Condições de KKT; Mercado local de energia; Microrredes; Equilíbrio de Nash; Eficiência de Pareto.

\footnotetext{
${ }^{1}$ Electrical and Computer Engineering School of Federal University of Goiás, Brazil

*E-mail: henriquetonha@yahoo.com.br
} 


\section{INTRODUCTION}

Increased energy consumption, the urbanization, the dismembered the energy supply chain, the pursuit of efficiency and sustainability, and the loss of traditional economies of scale through centralized generation (LASSETER; PAIGI, 2004), resulted in opportunities for consumers to participate more actively in the network. This participation can occur by demand-side management, demand response, and energy production through distributed energy resources (DERs).

In market, DERs participate directly or through intermediary entities, either individually or by aggregation as microgrids (MGs). MGs are a subsystem within defined area acting as a single entity. MGs can integrate renewable energy sources (RESs), conventional generators, energy storage systems (ESSs), main grid and loads (LASSETER; PAIGI, 2004; MENG et al., 2016). When the MG has power surplus, it can supply the grid as an independent energy producer (DOU et al., 2019). Therefore, MGs may be contracted for power supply and/or ancillary services as voltage control, backup supply, and network stability.

Configurations with more than one type of source are called hybrid MGs. In general, hybrid systems composed of renewable resources take advantage of the complementarity of sources, in this way, can contribute to the regularity of the system's supply during its operation.

From an economic point of view, Hanna et al. (2017) find that the changes from the pure distribution service (electric utilities) to the diversified system (electric utilities and MGs) are advantageous.

From the investor's perspective, the reason of MGs existence is to serve its own load at a lower cost than the utility companies. The next generation of retail electricity market will offer new business opportunities for prosumers (CHEN et al., 2018). Although the spread of prosumers could create an environment competitive on sector, there is evidence of market power in the segment (PEREZ et al., 2016). High financial investment for the MGs implementation and their remote location in the grid are suggestive examples of inequality on competition between them. DERs located at more remote points in the grid (i.e., farthest from the substation) have greater operational importance than less remote DERs, because the firsts improve power quality in less at_tractive portions for the utility companies to invest. However, DERs in more remote 
portions of the network suggests a smaller number of neighboring consumers to be served because the DER is farther away from the highest loads, therefore, smaller market share than DERs centrally located in the grid that have the potential to customers on several directly connected extensions.

The selfish profile of energy producers makes difficult the cooperation among them (TANG, et. al., 2017). The interaction among MGs involves the conflict of the market share, therefore game theory is a suitable methodology to analyze strategically the behavior of these agents. The objective of this analysis is to find the Nash equilibrium (NE), which is the desired behavior for all participants. The strength of the NE concept imposes a computational stalemate: not all games have pure equilibrium and those that do can give rise to search of high computational complexity

The convergence time of an algorithm for an equilibrium solution in games, in theory, varies according to the number of agents involved, the number of decision options, the type of game, the non-linearity of the payoff function, the decision environment that involves the rules and the conflict resolution strategy, among other factors (ABBOTT; KANE; VALIANT, 2005). Daskalakisi, Goldberg e Papadimitriou (2009) show the computational difficulty to obtain the NE. This difficulty for several approaches gives rise to searches for approximate solutions.

Admitting the remuneration of the power sold by MGs based on bilateral contracts, therefore, there are favorable prices for investor remuneration. This paper aims to propose a market model competition among MGs active in local energy market. MGs remotely installed in the grid participate of a static game on associated way. This virtual association seeks justice for market competition due to the importance of these MGs to power quality of the grid. These associate MGs share the local market with another locally better installed MG. The graphical game model is proposed to competition between remotely installed MGs and MG more centralized in the grid. Through the KKT conditions, the game is solved and NE and PE points are obtained in polynomial time. The model aims to remunerate the main agents of electric grid: MGs, utility companies, and consumers to reduce the potential disagreements among stakeholders.

In addition to the development of a graphical platform to allow visualization of $\mathrm{NE}$ and PE points and contribute to the reform of the electricity market other contributions are listed as follows:

- Boost investment in DERs, especially RESs, given that autonomous MGs participate intensively in the energy market. 
- Encourage MGs, particularly those remotely installed in the network to identify energy businesses opportunities.

- Promote fairness and equality on market share by strengthening the remote MGs in the network.

- Propose a competitive benefit model of multiple stakeholders: utility companies, consumers, and MGs.

\section{LITERATURE REVIEW}

MG can be defined as a set of DERs, ESSs, loads and coordinated agents that can operate connected or not to the grid, in low or medium voltage.

Due to the spread of DERs, utility companies may innovate in their business models. They can support MGs with professional knowledge and ensure energy equilibrium. It is from this perspective that the Distribution System Operator (DSO) has the role of managing the energy flows and offsets involving MGs in the retail market as in Fig. 1. The DSO can negotiate preferentially with suppliers that use renewable resources in their portfolio. Unlike Boloukat e Foroud (2018), where the DSO is considered a protagonist with decision-making power over the MGs, in this paper, the DSO is a referee of contracts with energy and monetary settlement skills.

Fig. 1 - The market topology of exporting MGs

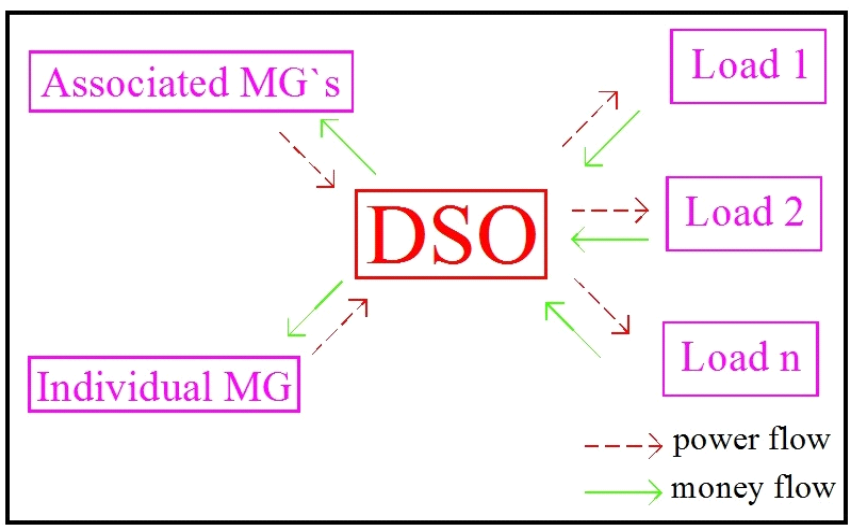

Font: Adapted from Boloukat and Foroud (2018) 
In order to guarantee the reliability of the electrical grid, the hybrid MR needs a robust power management system. In this sense, the Multi Agent System (MAS) based on control mode becomes efficient to facilitate the decision-making process within MGs (KHAN et al., 2019). The MAS structure is a composition of multiple intelligent agents (machines) that interact with each other, offering robustness and flexibility to the managed system. These agents work autonomously and are employed to strengthen the system as they solve problems that could not be solved by a single agent (LASSETER; PAIGI, 2004). Fig. 2 shows the internal macro design of interaction among intelligent agents on decentralized control arrangement performed by the Hybrid Microgrid Operator.

Fig. 2 - Architecture model MAS in hybrid MG

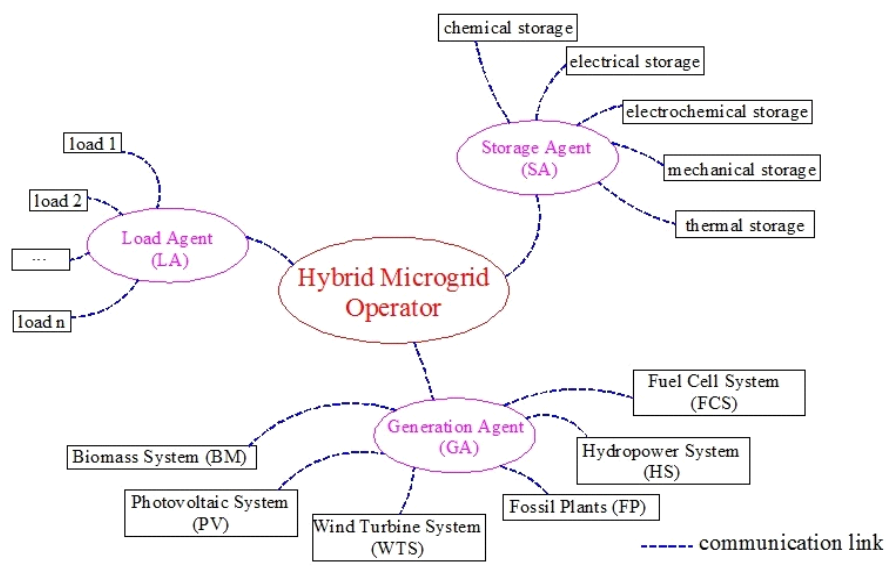

Considering the complexity of conflict resolution in electricity markets from game theory, approximate methods (ZAREI; SALAMI, 2016; MARZBAND et al., 2016) and use of bilevel model to reduce the search space of problem (HINCAPIE; GALLEGO; MANTOVANI, 2019; XU; ZHANG, 2020; QUASHIE et al., 2018; Cui et al., 2019; Lee et al., 2015; TANG et al., 2017; FLEISCHHACKER et al. 2019; GUO et al. 2021) are presented.

Once the agents are in EN do not have incentives to deviate, an approximate Nash means a low incentive to do. For a continuous game, Zarei e Salami (2016) discretize the space of strategies and resort for modified solving matrix game to decrease the complexity of an auction game. Although discrete strategies contribute to reduce search time, there are a risk of losing some equilibria. The Nikaido-Isoda function and the relaxation algorithm are used in the retail market for sale power surplus in Marzband et al. (2016). 
In this case, small prosumers come together to become big enough to participate in the market.

The bi-level optimization model also called hierarchical optimization, which one of the players considered commander (leader) decides, and then the other agents (followers) decide in sequence, is also known as sequential play. This hierarchy process is used sometimes for reasons inherent to the processes, sometimes for computational convenience, and even if the second option is a consequence of the first, if necessary. The follower only optimizes its strategy as a result of the choice of leader, and thus reduces the algorithm's search space (HINCAPIE; GALLEGO; MANTOVANI, 2019).

Table 1 shows the positioning of players in bi-level games involving MRs and others electrical system agents.

Table 1 - Some works involving bi-level game for the distributed energy market

\begin{tabular}{|c|c|c|c|}
\hline Authors & Leader & Follower & Main objective \\
\hline $\begin{array}{l}\text { Hincapie; Gallego; } \\
\text { Mantovani, } 2019\end{array}$ & distribution grid & DERs & minize investiment cost \\
\hline $\mathrm{Xu}$; Zhang, 2020 & distribution grid & MGs & reduce active loss \\
\hline $\begin{array}{l}\text { Quashie et al., } \\
2018\end{array}$ & MGs & DSO & minize investiment cost \\
\hline Cui et al., 2019 & MGs & DERs & reduce active loss \\
\hline Lee et al., 2015 & MGs & Energy buyers & utility of buyers and MGs \\
\hline Tang et al., 2017 & DERs & electric utilities & Maximize DER profit \\
\hline $\begin{array}{l}\text { Fleischhacker et al. } \\
2019\end{array}$ & DERs & consumers & minize energy cost \\
\hline Guo et al. 2021 & DSO & MGs & $\begin{array}{l}\text { optimal energy } \\
\text { management }\end{array}$ \\
\hline
\end{tabular}

\section{THE MODEL}

\subsection{CHARACTERIZATION OF THE PROBLEM}


In multi-microgrids systems of several owners, it will be very unlikely to carry out cooperative management between them, therefore it is proposed a non-cooperative model considering the competitive relationship among MGs. It is assumed that prosumers have a strictly growing desire to remunerate themselves.

Considering the economic motivation for dispatch, it is proposed a multi-objective optimization problem (1) to maximize injected active power $x_{i}$ and $x_{-i}$, respectively for $G$ associated and large MGs. A set of constraints satisfy the technical limitations in grid with $p$ buses. Comparing to remotely installed MGs, it is assumed that the best locally installed MG is considered the large MG. It will be analyzed the participation of MGs as power surplus, i.e., exporting to the grid. In the model, the $\mathrm{G}$ remote MGs are associated virtually to compete with the large MG. The loss profile for the operation of a DER on bus in the network is shown in Fig. 3. The mode of export is considered on growing part of the curve located to the right of the minimum loss point $P_{\text {loss }}^{\min }$ and the same loss value obtained without the power injection agents $P_{l o s s \backslash i,-i}$.

$$
\begin{gathered}
\text { maximize }\left[x_{i}, x_{-i}\right] \\
\text { subject to } \\
I_{a, b} \leq A m p_{a, b}, \quad a=1,2, \ldots p ; b=2,3, \ldots p-1 \\
P_{\text {loss }}^{\min } \leq \sum_{a=1}^{p} \sum_{b=2}^{p-1} P_{\text {loss }_{a, b}} \leq P_{\text {loss } \backslash i,-i} \\
V_{a}^{\min } \leq V_{a} \leq V_{a}^{\max }, a=1,2, \ldots p \\
x_{i}=\sum_{g=1}^{G} x_{i_{g}}, g=1,2, \ldots G \\
P_{\text {loss }}=\min \left(P_{\text {loss }}, x_{i} \mid x_{-i}\right)
\end{gathered}
$$

In (1), $I_{a, b}$ is the current flow from bus $a$ to bus $b, A m p_{a, b}$ and $P_{l o s s_{a, b}}$ are respectively the electric ampacity of conductor and loss between $a$ and $b$ buses. $P_{\text {loss } \backslash i,-i}$ is the loss of network without DERs. $V_{a}$ is the voltage at bus a in per unit (pu) that minimum and maximum limits are respectively $V_{a}^{\min }$ and $V_{a}^{\max }$. For equal power, the smallest loss is selected.

From the selection of the location and power factors of the MGs, the Algorithm 1 is proposed for the solution of the multi-objective optimization problem (1). A vector $\ddot{X}$ 
is filled with the smallest own load between the MGs and its size is equal to the number of them: $\mathrm{G}+1$. This measure guarantees an approximation to the left of the point $P_{\text {loss }}^{\min }$ in the Fig. 3, which begins the evaluation through of Algorithm 1.

Fig. 3 - Quadratic curve of DER operation as a function of loss

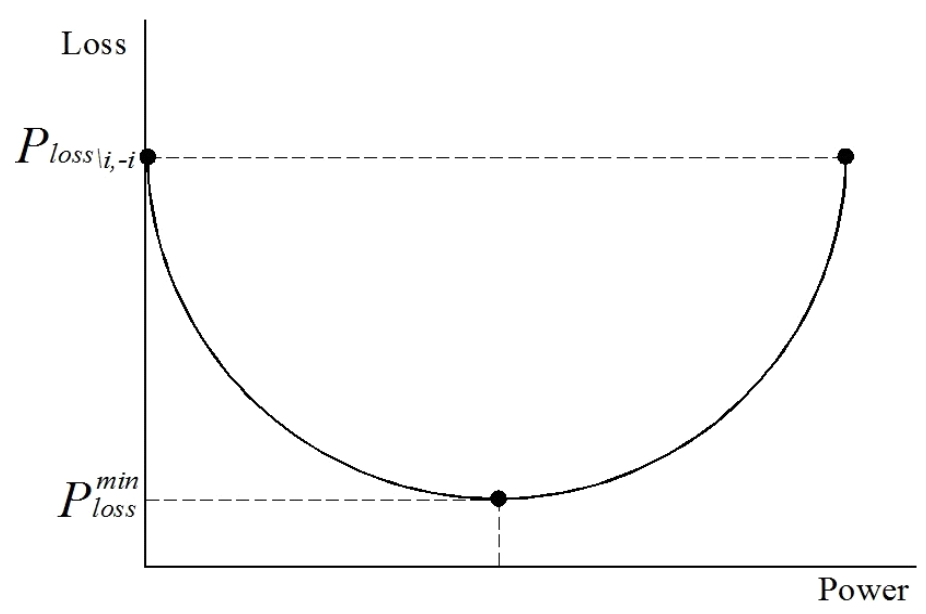

\footnotetext{
Algorithm 1: Problem solving procedure (1)

Input : $\ddot{X}=\left[\left(X_{i}, X_{-i}\right)\right], X_{i}=\left[x_{i_{1}}, x_{i_{1}}, \ldots x_{i_{G}}\right], X_{-i}=\left[x_{-i_{1}}, x_{-i_{1}}, \ldots x_{-i_{G}}\right], A m p_{a, b}$ $a=1,2, \ldots p ; b=2,3, \ldots p-1, V_{a}^{\min } \leftarrow 0.93, V_{a}^{\max } \leftarrow 1.05$

Output: $\ddot{X}, P_{\text {loss }}$
}

Run the base case (without MGs) and get $P_{\text {loss } \backslash i,-i}$

Repeat

Run the load flow for $\ddot{X}$;

Check if loss decrease and keep the smaller one until it grows: $P_{\text {loss }}^{\min }$;

Increment $\ddot{X}$;

Until the loss grows;

Repeat

Run the load flow for $\ddot{X}$;

Get $P_{\text {loss }}, I_{a, b}, V_{a}$;

Verification of inequality restrictions of (1)

Get $P_{\text {loss }}, \ddot{X}$;

Increment $\ddot{X}$;

Until $\forall$ inequality restrictions of (1) be violated 
The following section presents a graphical model that requires two goods, therefore it is necessary to replace loss for loss reduction $\left(y_{i}\right)$. To each feasible $x_{i}$, the loss reduction can be calculated by (2). Likewise, it can be obtained $y_{-i}$.

$$
y_{i}=\left(\frac{\sum_{a=1}^{p} \sum_{b=2}^{p-1} P_{\text {loss }_{a, b}-P_{\text {los } \backslash i,-i}}}{P_{\text {loss } \backslash i,-i}} \mid x_{-i}\right)
$$

\subsection{GRAPHIC TOOL}

The Edgeworth box in Fig. 4 is a graphical visualization, which represents all possible allocations of goods (EDGEWORTH, 1881). After solving (1) and fixing an injected power for each agent (associated and large MGs) typical operating curves such as $A$ and $B$ in Fig. 4 are obtained. To the i-axis (bottom left), the concave curve $A$ corresponds the operation of the associated MGs for a constant $x_{-i}$ (operation of the large MG). Otherwise, to the player-i-axis (upper right), the concave curve $B$ corresponds the operation of the large MG for a constant $x_{i}$ (operation of the associated MGs).

Fig. 4 - Conic like and preference structure in Edgeworth box

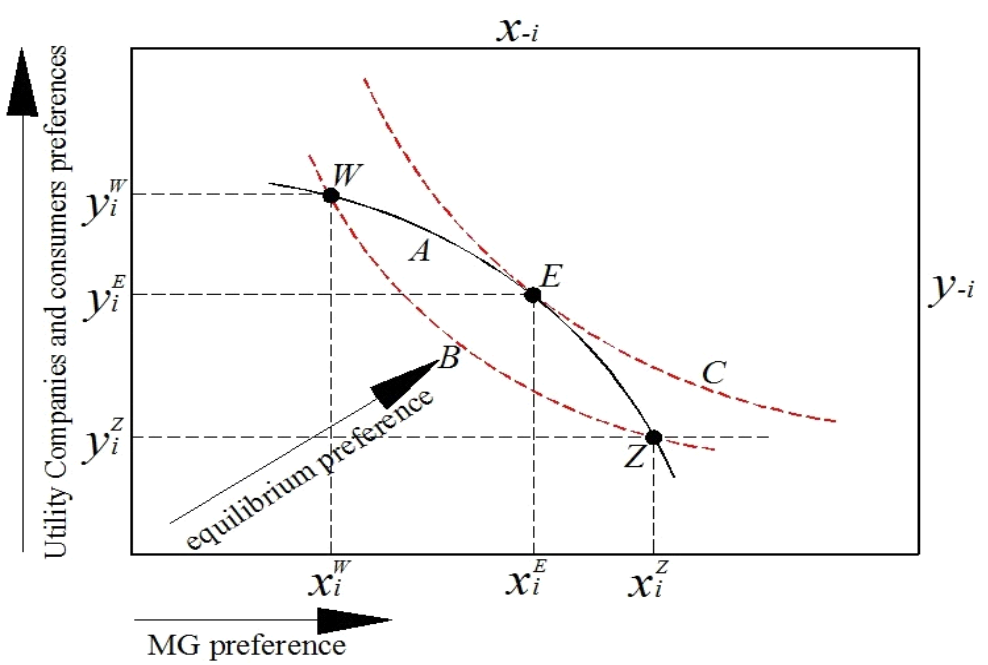

In this model, loss reduction is considered the remuneration of the utility companies and consumers. The utility companies gain in quality, image, and 
improvement operational problems that avoid sanctions imposed by the regulator. As the cost of loss is reduced, consumers benefit from reduced energy bills.

As MGs earn by selling energy, therefore they prefer to operate in the direction shown in Fig. 4 with $x_{i}^{Z}>x_{i}^{E}>x_{i}^{W}$. The utility companies and consumers prefer high loss reduction, such that $y_{i}^{W}>y_{i}^{E}>y_{i}^{Z}$ as shown in the Fig. 4. It is assumed that the convex curve in relation to each axis provides the utility $(U)$ of each player. The curves $B$ and $C$ provide utility for the $\mathrm{i}$-axis and curve $A$ provides utility for the -i-axis. Therefore, midpoints of the curve are preferable to extremes. From the Fig. 4, it is observed that for i-axis $U_{i}\left(x_{i}^{E}, y_{i}^{E}\right)>U_{i}\left(x_{i}^{Z}, y_{i}^{Z}\right)$ and $U_{i}\left(x_{i}^{E}, y_{i}^{E}\right)>U_{i}\left(x_{i}^{W}, y_{i}^{W}\right)$ because the curve $C$ is more distant from the origin of the $\mathrm{i}$-axis than $B$, therefore $C$ provides a greater utility than $B$. Thereby, the point $E$ corresponds to the maximum possible utility. The same analysis is admitted for the player-i-axis.

In Fig. 4, the points $W$ and $Z$ correspond of the conic-like vertex obtained by the intersection of the most distant curves $A$ and $B$. If the agents are rational, an orthogonal vector from the points $W$ and $Z$ towards the center of the conic-like figure is desirable for all players, because it increases everyone's utility and results in a stable equilibrium. The conic-like formed by curves $A$ and $B$ is a finite union of convex hulls (MILLER, 2000).

Neumann e Morgenstern (1944) define a game as the totality of rules that describe it. Whether board, sporting or commercial games, the existence of rules is the first condition of a competitive and inclusive environment. It must be the minimum enough to make the equilibrium game. In this model, the operation can be given by the concave or convex curve, but the utility only by the convex. Each operating equilibrium point has two possible ways of operation. The point E in Fig. 4 corresponds of two NE points, named modes 1 and 2 .

- The mode 1 is illustrated in the Fig. 5.a, whose player $i$ (Associated MGs) operation is given by the $\mathrm{i}$-axis box with $x_{i}^{\prime \prime}>x_{i}^{\prime}>x_{i}$ and $y_{i}^{\prime \prime}>y_{i}^{\prime}>y_{i}$ for the utility companies and consumers. The large MG (player $-i$ ) operates by curves: $A, B$, and $C$ with $\bar{x}_{-i}^{\prime \prime}>\bar{x}_{-i}^{\prime}>\bar{x}_{-i}$.

- In mode 2 , the player $-i$ operates through the $-\mathrm{i}$-axis box with $x_{-i}^{\prime \prime}>x_{-i}^{\prime}>x_{-i}$ and $y_{-i}^{\prime \prime}>y_{-i}^{\prime}>y_{-i}$ for the utility companies and consumers as shown in Fig. 5.b. The associated MGs (player $i$ ) operates by curves $\mathrm{A}, \mathrm{B}$, and C with $\bar{x}_{i}^{\prime \prime}>\bar{x}_{i}^{\prime}>\bar{x}_{i}$. 
Fig. 5 - Game setup modes

Fig. 5.a - Mode 1

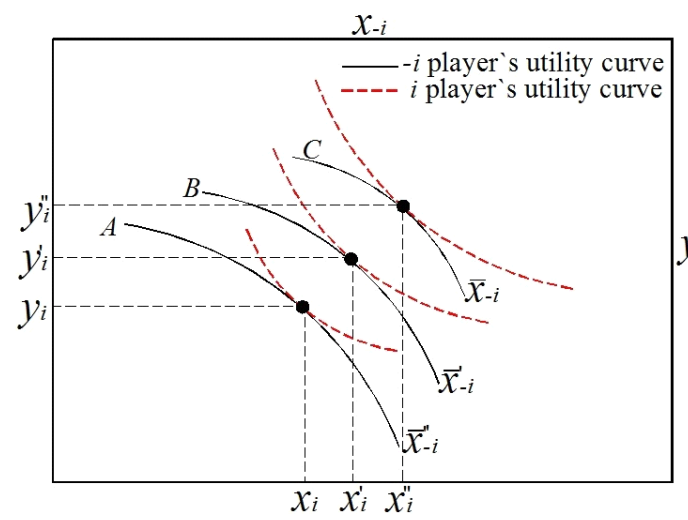

Fig. 5.b - Mode 2

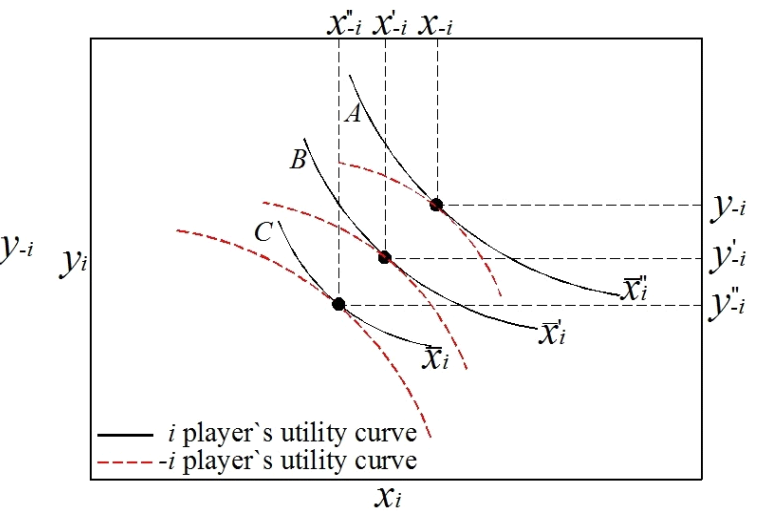

\section{OBTAINING THE NE}

By the power flow and the graphical perspective of the Edgeworth box as Fig. 4, it is possible $\left(x_{i}, x_{-i}\right) \rightarrow\left(y_{i}, y_{-i}\right)$ therefore, $\left(x_{i}, x_{-i}\right) \triangleq\left(y_{i}, y_{-i}\right)$. The utilities are mutually exclusive, if the injected power of one player increases, the utility of the other decreases, and viceversa. The utility function is the payoff of player. Additionally, as the utility of a player (MG) is given by the convex curve to its axis, thus, $U_{i}=f\left(x_{-i}, y_{-i}\right)$ and $U_{-i}=f\left(x_{i}, y_{i}\right)$. From the normalization and nonlinear approximation of $\ddot{X}$ (Algorithm 1 ), the $\mathrm{i}$-axis box utility function is given by $U_{i}=f\left(x_{-i}, y_{-i}\right)=\frac{1}{X_{-i}^{T} A_{-i} X_{-i}}=\bar{x}_{i}$ where $X_{-i}=\left[x_{-i}, y_{-1}, 1\right]^{T}$ and $A_{-i}$ is a $(\bar{n}+1) x(\bar{n}+1)$ matrix with the third term of the third row and column null. Likewise, the $-\mathrm{i}$-axis box utility function is given by $U_{-i}=$ $f\left(x_{i}, y_{i}\right)=\frac{1}{X_{i}^{T} A_{i} X_{i}}=\bar{x}_{-i}$ where $X_{i}=\left[x_{i}, y_{1}, 1\right]^{T}$ and $A_{i}$ is a $(\bar{n}+1) x(\bar{n}+1)$ matrix with the third term of the third row and column null. The analytical expression of the conic in Fig. 4 is $g(x, y)=X^{T} B X \quad$ with $B=\left[\begin{array}{ll}B_{1,1} & B_{1,2} \\ B_{2,1} & B_{2,2}\end{array}\right]$ a $(\bar{n}+1) x(\bar{n}+$ 1) symmetric block matrix, and $B_{1,1}$ a $(\bar{n}) \times(\bar{n})$ symmetric positive definite submatrix. According to eigenvalues of $B$, the conic is classified as an ellipse.

Whether the players are rational, they have a convex objective function and share a convex constraint, thereby a convex problem can be given by (3). In a convex programming problem, the KKT conditions (4-12) are sufficient for a global maximum (BAZARRA; SHERALI; SHETTY, 2006). 


$$
\begin{gathered}
\text { maximize }\left[U_{i}, U_{-i}\right] \\
\text { subject to } \\
g(x, y) \leq 0 \\
x_{i}, x_{-i}, y_{i}, y_{-i}>0 \\
x_{i}\left(\frac{\partial f_{i}\left(x_{i}, y_{i}\right)}{\partial x_{i}}-\mu_{x_{i}} \frac{\partial g_{i}\left(x_{i}, y_{i}\right)}{\partial x_{i}}\right)=0 \\
y_{i}\left(\frac{\partial f_{i}\left(x_{i}, y_{i}\right)}{\partial y_{i}}-\mu_{y_{i}} \frac{\partial g_{i}\left(x_{i}, y_{i}\right)}{\partial y_{i}}\right)=0 \\
x_{-i}\left(\frac{\partial f_{-i}\left(x_{-i}, y_{-i}\right)}{\partial x_{-i}}-\mu_{x_{-i}} \frac{\partial g_{-i}\left(x_{-i}, y_{-i}\right)}{\partial x_{-i}}\right)=0 \\
y_{-i}\left(\frac{\partial f_{-i}\left(x_{-i}, y_{-i}\right)}{\partial y_{-i}}-\mu_{y_{-i}} \frac{\partial g_{-i}\left(x_{-i}, y_{-i}\right)}{\partial y_{-i}}\right)=0 \\
\mu_{x_{i}}\left(g_{i}\left(x_{i}, y_{i}\right)\right)=0 \\
\mu_{y_{i}}\left(g_{i}\left(x_{i}, y_{i}\right)\right)=0 \\
\mu_{x_{-i}}\left(g_{-i}\left(x_{-i}, y_{-i}\right)\right)=0 \\
\mu_{y_{-i}}\left(g_{-i}\left(x_{-i}, y_{-i}\right)\right)=0 \\
x_{i}, x_{-i}, y_{i}, y_{-i}, \mu_{x_{i}}, \mu_{y_{i}}, \mu_{x_{-i}}, \mu_{y_{-i}} \geq 0
\end{gathered}
$$

Algorithm 2 is based on decreasing of volume the ellipse. As $B_{1,1}$ is a symmetric positive definite submatrix, the initial volume of ellipse is given by $V\left(E_{0}\right)=$ $\operatorname{det}\left(B_{1,1}{ }^{1 / 2} w_{n}\right)$ where $w_{n}$ is the volume of the $\bar{n}$-dimensional unit ball. The matrix $\mathrm{D}$ is $D=\operatorname{diag}\left(\lambda_{1}, \ldots \lambda_{\bar{n}}, \lambda_{\bar{n}+1}\right)$ with the firsts $\bar{n}$ elements are positive and the last $\bar{n}+1$ is negative. As $1 / \lambda_{i}$ with $i=[1,2, \ldots \bar{n}]$ is the radii of the conic, the reduction of volume applied to $\lambda_{i}$ for $\bar{n}$ dimension of the space can be given by : $c_{\bar{n}}=\frac{\bar{n}}{\bar{n}+1}\left(\frac{\bar{n}^{2}}{\bar{n}^{2}+1}\right)^{\frac{(\bar{n}-1)}{2}}<$ 1 used in (SHAH; MITCHELL; KUPFERSCHMID, 2001). 
Algorithm 2: Procedure for obtaining equilibrium points by constraint space reduction Input : Normalize $\left[\left(X_{i}, X_{-i}\right)\right], B^{0} \bar{n} \leftarrow 2, k \leftarrow 0$

output: $\left[x_{i}^{k}, x_{-i}^{k}, y_{i}^{k}, y_{-i}^{k}\right]$

Do $\lambda_{i}^{0}=P^{-1} B P$, where $P$ is a square orthogonal matrix;

Apply (4)-(12)

|| Update the restriction and solving the multiobjective problem

Repeat

Apply (4)-(12)

$k=k+1$

$\lambda_{i}=\lambda_{i}^{0} /_{C_{\bar{n}}^{k}{ }^{1 / \bar{n}+1}} i=1, \ldots, \bar{n} ;$

$B_{B_{i, j \in B \backslash B \bar{n} \times \bar{n}}}=P^{-1} D P$

Apply (4)-(12)

Untill $\exists \mu: \mu \in \Re_{+}$

\section{RESULTS AND DISCUSSION}

A modified IEEE 13-bus distribution network is shown in Fig. 6 that is used as a case study (IEEE, 2020). The MG 1, MG 1 is connected on bus 675 to supply the original bus load. As the bus 675 is the largest neighboring load bus and located in the central portion of branch $671-675$, the MG 1 is considered the large MG. The other $\mathrm{MGs} \mathrm{MG}_{2}$ and $\mathrm{MG}_{3}$ are more remotely installed in relation to $\mathrm{MG}_{1}$, so they are considered associated MGs. These three MGs make up the local energy market under analysis.

A loading scenario for MGs is listed on the Table 2. The distance mentioned refers to bus 675 of the grid. The MGs operate with unit power factor and the switch located between the buses 671 and 692 operates closed. 
Fig. 6 - A modified IEEE 13-bus

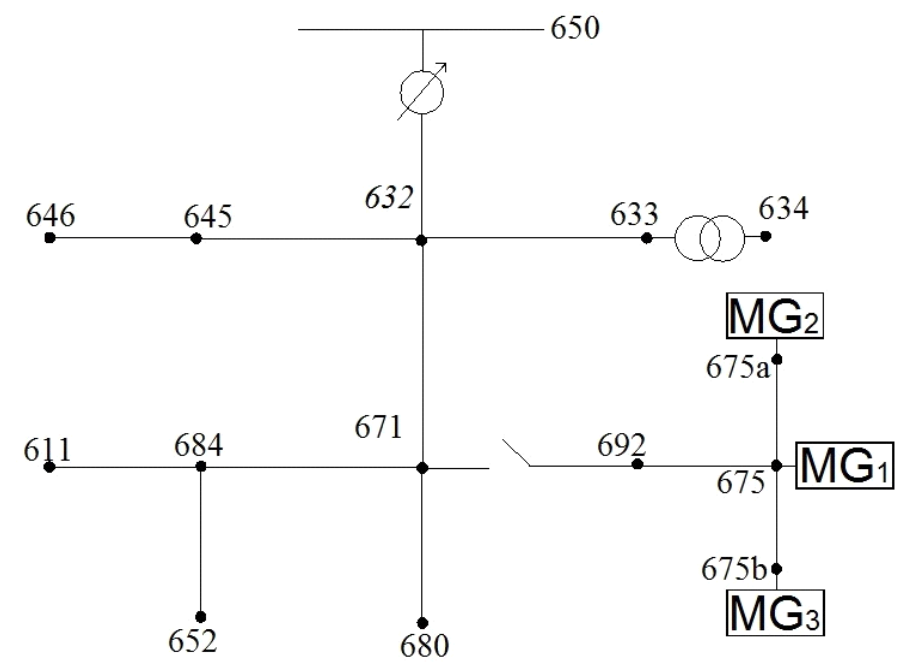

Font: Adapted from IEEE (2020)

Table 2 - Load and distance at 675 bus

\begin{tabular}{|c|c|c|c|c|c|c|c|}
\hline \multirow{3}{*}{ MG } & \multicolumn{7}{|c|}{ Load } \\
\hline & \multicolumn{2}{|c|}{ phase a } & \multicolumn{2}{|c|}{ phase b } & \multicolumn{2}{|c|}{ phase c } & \multirow{2}{*}{ distance } \\
\hline & $\mathrm{kW}$ & $\mathrm{kVAr}$ & $\mathrm{kW}$ & $\mathrm{kVAr}$ & $\mathrm{kW}$ & $\mathrm{kVAr}$ & \\
\hline 1 & 480 & 190 & 68 & 60 & 290 & 212 & 50 \\
\hline 2 & 185 & 90 & 48 & 40 & 210 & 92 & 600 \\
\hline 3 & 125 & 90 & 38 & 20 & 110 & 72 & 400 \\
\hline
\end{tabular}

We assume that MGs are hybrid, therefore, these agents are able to sustain the selling contracts backed through the mix of renewable and non-renewable resources. In Edgeworth box, a possible set of operation curve for the problem (1) and the convex set for the system under study is illustrated in Fig. 7. The ordinate axes relate the total loss reduction according to (2). The convex set in the figure is formed by the most distant concave curve: blue continues for the $\mathrm{i}$-axis and red discontinues for the -i-axis. By nonlinear fit, these curves are given by (13) and (14). The initial conic has the normalized matrix (15). 
Fig. 7 - Edgeworth box for a modified IEEE 13-bus system

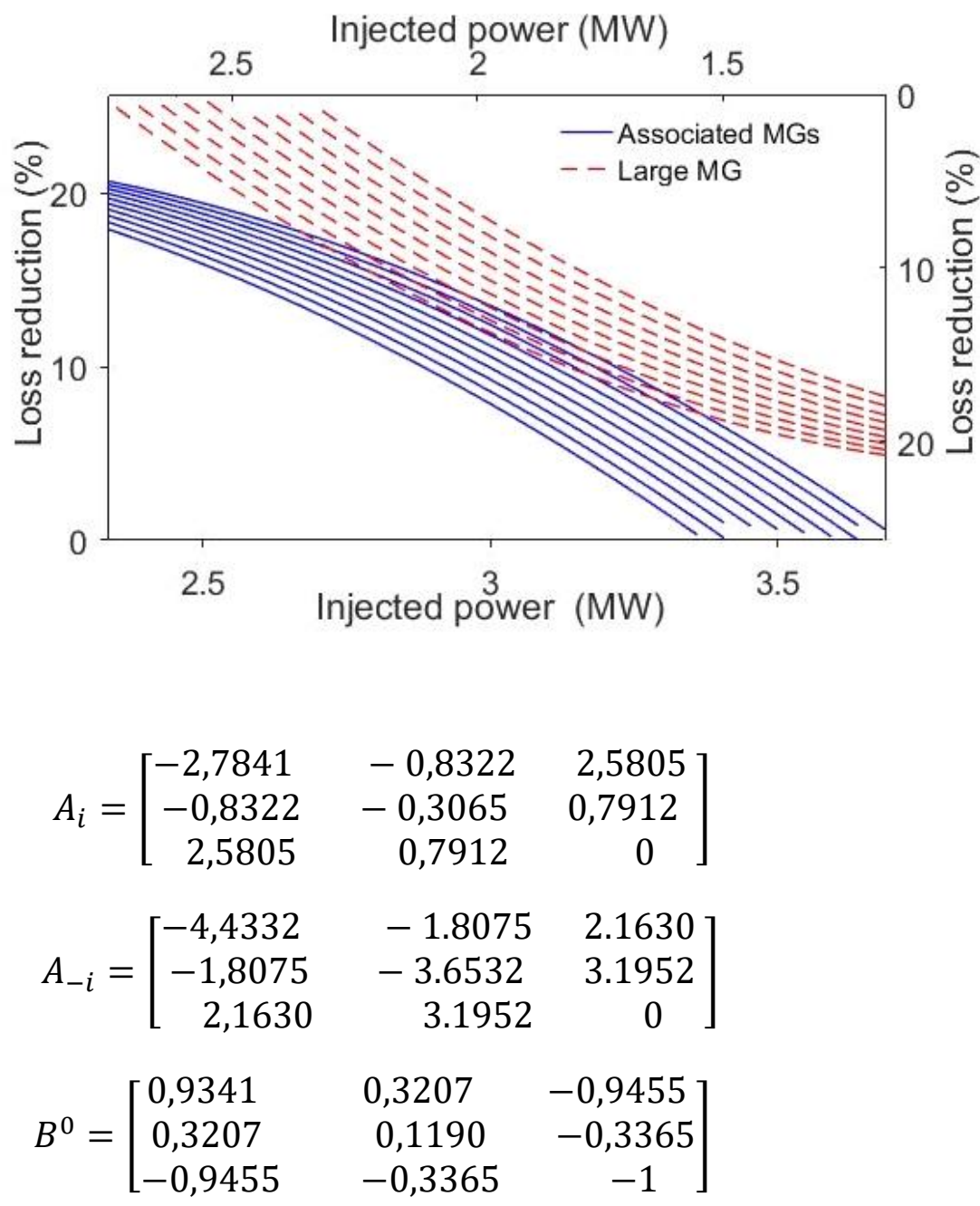

The NE can also be obtained by fixed point theorems, therefore it can be expected that all the NE points are non-degenerate (Rosen, 1965). The point $E$ in Fig. 4 is obtained for all curves, this result can be observed in Fig. 8 for modes 1 and 2 of operation. These are the contract curves that contain all NE and PE points. The Fig. 8 shows the operation profile of MGs and the benefits of the utility companies and consumers for the two modes of operation. Any NE point provides two possibilities for operation, giving to DSO the freedom to choose the best mode of operation. For mode 1 of operation, the associated MGs can generate from 2.90 to $3.14 \mathrm{MW}$, for the large MG the power range is 1.19 to 1.24 MW and the loss reduction range of $12.12 \%$ to $13.24 \%$. Similarly, to the mode 2 , the associated MGs operate of 2.30 to $2.41 \mathrm{MW}$, the large MG operates of 1.80 to 1.95 MW and the loss reduction is $13.60 \%$ to $14.93 \%$. For example, if the DSO opts for a $14 \%$ 
of loss reduction, the associated and the large MG operate respectively with $2.375 \mathrm{MW}$ and $1.832 \mathrm{MW}$ for mode 2.

The association of remotely installed MGs on the model favors their participation in the local market. This participation promotes justice for small prosumers located in remote portions of the network, which have greater operational importance than central prosumers.

The present simulation was performed on a processor computer Intel Core i5 with 3.1 Ghz of processing speed and $16 \mathrm{~GB}$ of RAM, with average approximate time of $580 \mathrm{~s}$ for solution of multiobjective processes: (1) and (3).

Once operating on the contract curve, no agent can increase its utility unless decrease other. PE and NE are a strong concept, because they mean that mutual trade gains are exhausted. The PE frontier contains the non-dominated values of the objective functions and it is illustrated in Fig. 9, which axes represent the utility. The i-axis corresponds to the associated MGs, the another (-i-axis) represents the large MG together with the utility companies and the consumers. In another way, the -i-axis represents only the large MG and the i-axis aggregates the utilities of associated MGs, utility companies, and consumers according to modes of operation.

Fig. 8 - Operation contract curves
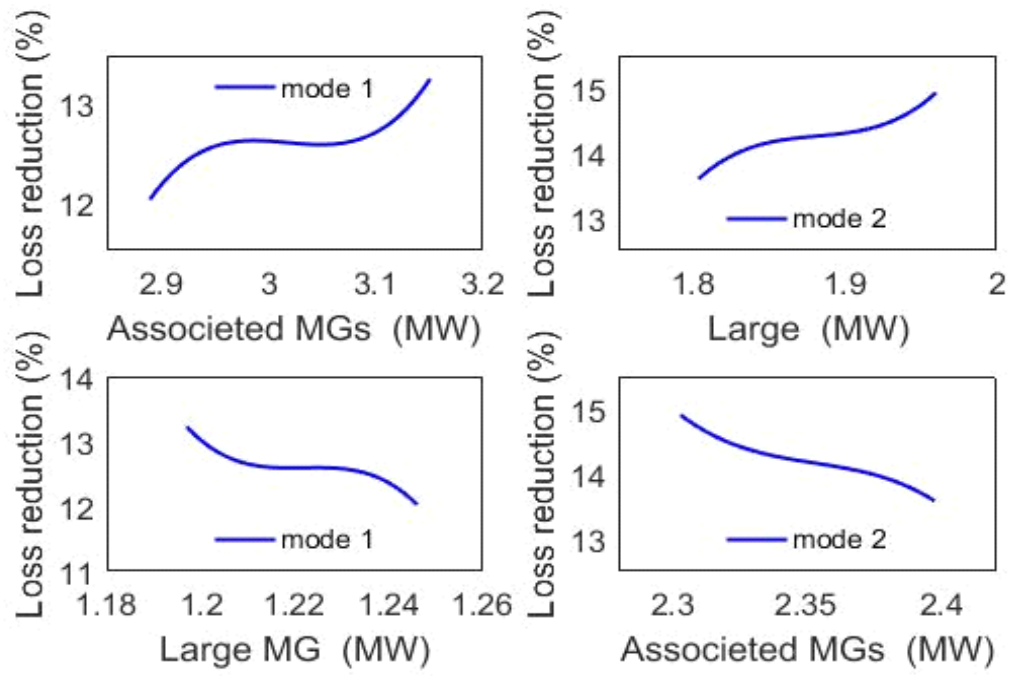
Fig. 9 - Pareto border for utility of axes on the box

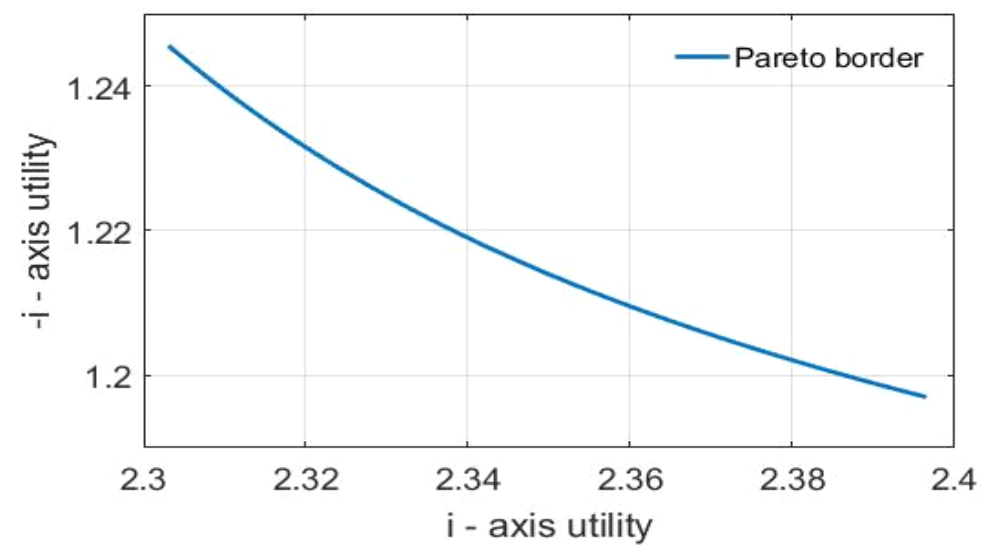

Nash gains are mutually advantageous for the agents involved. The greatest utility gain for players is observed when they are located at the intersection of the curves of lesser utility, i.e., points such as $\mathrm{W}$ or $\mathrm{Z}$ in the Fig 4. Using the proposed conical volume reduction technique to solve the problem (3) an internal orthogonal path move these points towards an NE located in center of the ellipse. These utility gains are the largest possible for both axes and is shown in Fig. 10. Other utility gains are verified for any point of possible operation, in which an allocation path moves towards the contract curve. As utility of i-axis involves the participation of the associated MGs, these MGs are also privileged by the model for obtaining greater utility gain. For this example, the gain of utility involving associated MGs is $88 \%$ greater than that involving large MG.

Fig. 10 - Example of NE development (above) and gain of utility for the axes (below)
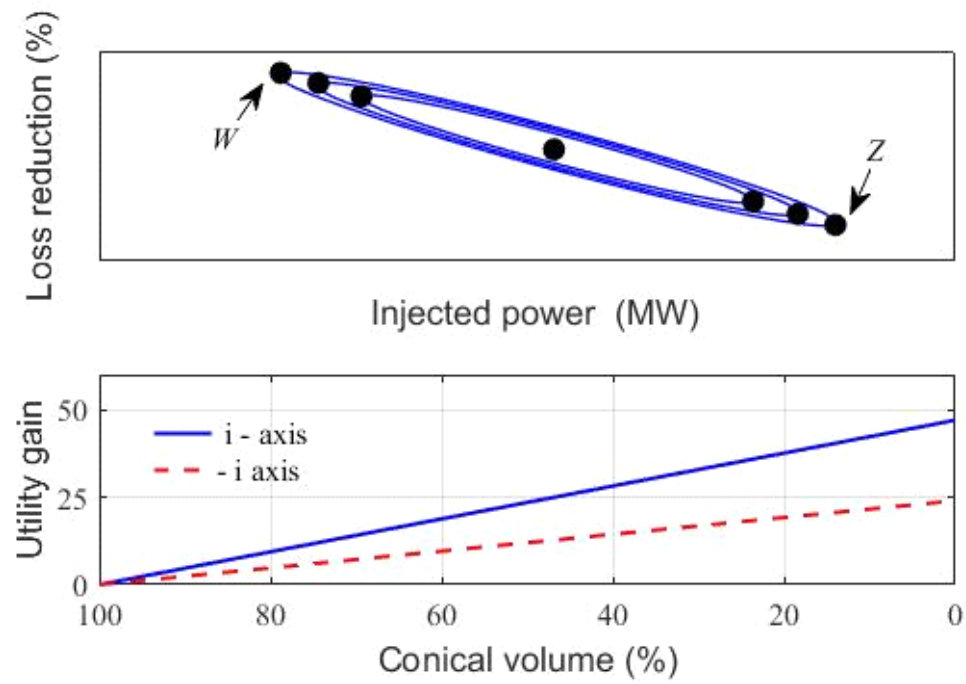


\section{CONCLUSIONS}

The energy systems of the future are planned to cover several autonomous entities that interact each other with the network and other consumers. The reduction in costs involved in hybrid systems due to the rapid expansion of global markets should expand investments for generation focused on energy trade.

The proposed methodology aims to address the market share of MGs according to their inequalities. The Edgeworth box allows obtain visually NE and PE results. The virtual association among MGs remotely installed in the network aims a market justice for the participation of these agents.

To infinite games, the strategy search space is usually large, therefore special techniques are needed to search. The concave/convex condition of the operation/utility function associated a graphical representation provides computationally tractable mechanisms for obtaining an analytical NE and PE results.

We analyzed a macro perspective for the game where MGs compete each other. For future work, the economic dispatch of hybrid MG acting as a firm will be analyzed as a cooperative game.

\section{ACKNOWLEDGMENT}

This work was supported by Coordination of Improvement of Higher Education Personnel of Brazil (Capes) in partnership with Research Support Foundations of Goias state (Fapeg). The authors thank these institute for their support.

\section{REFERENCES}

ABBOTT, T.; KANE, D.; VALIANT, P. On the complexity of two-player win-lose games. In: 46th Annual IEEE Symposium on Foundations of Computer Science (FOCS'05) 2005, Pittsburgh, PA, USA. Anais[...] Pittsburgh, 2005. p. 113-122.

Bazarra, M.S., Sherali, H.D., Shetty, C.M. Nonlinear Programming. Theory and Algorithms. Third ed., Wiley-Interscience, USA, 2006.

BOLOUKAT, M. H. S.; FOROUD, A. A. Multiperiod planning of distribution networks under competitive electricity market with penetration of several microgrids, part $\mathrm{i}$ : 
Modeling and solution methodology. IEEE Transactions on Industrial Informatics, v. 14, n. 11, p. 4884-4894, 2018.

CHEN, T. et al. The next-generation u.s. retail electricity market with customers and prosumers - A bibliographical survey. Energies, v. 11, n. 1, 2018.

CUI, S. et al. A two-stage robust energy sharing management for prosumer microgrid. IEEE Transactions on Industrial Informatics, v. 15, n. 5, p. 2741-2752, 2019.

DASKALAKISI, C.; GOLDBERG, P. W.; PAPADIMITRIOU, C. H. The complexity of computing a Nash equilibrium. SIAM Journal on Computing, v.39(1) p. 195-259, 2009.

DOU, C. et al. Multi-agent-system-based bi-level bidding strategy of microgrid with game theory in the electricity market. Electric Power Components and Systems, v. 47, n. 8, p. 703-719, 2019.

EDGEWORTH, F. Mathematical Psychics. London: C. K. P., 1881.

FLEISCHHACKER, A. et al. Sharing solar pv and energy storage in apartment buildings: re_source allocation and pricing. IEEE Transactions on Smart Grid, v. 10, n. 4, p. 3963-3973,2019.

GUO, C. et al. Optimal energy management of multi-microgrids connected to distribution sys_tem based on deep reinforcement learning. International Journal of Electrical Power Energy Systems, v. 131, p. 107048, 2021.

HANNA, R. et al. Evaluating business models for microgrids - interactions of technology and policy. Energy Policy, v. 103, p. 47-61, 2017.

HINCAPIE, R. A.; GALLEGO, R. A.; MANTOVANI, J. R. A decomposition approach for integrated planning of primary and secondary distribution networks considering distributed generation. International Journal of Electrical Power Energy Systems, v. 106, p. $146-157,2019$.

IEEE. Institute of Electrical and Electronics Engineers. https//site.ieee.org/pestestfeeders/ - Access on February 15, 2020. 2020

KHAN, M. W. et al. Optimal energy management and control aspects of distributed microgrid using multi-agent systems. Sustainable Cities and Society, v. 44, p. 855 870, 2019.

LASSETER, R. H.; PAIGI, P. Microgrid - A conceptual solution. In: 2004 IEEE 35th Annual Power Electronics Specialists Conference 2004, Aachen, Germany. Anais[...] Aachen, 2004 v. 6, p. 4285-4290.

LEE, J. et al. Distributed energy trading in microgrids - a game-theoretic model and its equilibrium analysis. IEEE Transactions on Industrial Electronics, v. 62, n. 6, p. 3524-3533, 2015. 
MARZBAND, M. JAVADI M, DOMINGUEZ-GARCIA JL, MIRHOSSEINI

MOGHADDAM M. Non-cooperative game theory based energy management systems for energy district in the retail market considering der uncertainties. IET Generation, Transmission Distribution, v. 10 (10), p. 2999-3009, 2016.

MENG, L. et al. Microgrid supervisory controllers and energy management systems - A literature review. Renewable and Sustainable Energy Reviews, v. 60, p. 1263-1273, 2016.

MILLER, R. Optimization foundations and applications. Wiley Interscience, 2000.

NEUMANN, J. V.; MORGENSTERN, O. Games and economic behavior. Princeton University Press, 1944.

PEREZ, A. P.; SAUMA, F. D. M. E. E.; HOBBS, B. F. The economic effects of interregional trading of renewable energy certificates in the U.S. Wecc. The Energy Journal, v. 37, n. 4, 2016.

QUASHIE, M. et al. Optimal planning of microgrid power and operating reserve capacity. Applied Energy, v. 210, p. 1229-1236, 2018.

ROSEN, J. Existence and uniqueness of equilibrium points for concave n-person games. Econometrica, v. 33, n. 3, p. 520-534, 1965.

SHAH, S.; MITCHELL, J. E.; KUPFERSCHMID, M. An ellipsoid algorithm for equality_constrained nonlinear programs. Computers Operations Research, v. 28, n. 1, p. $85-92,2001$.

TANG, Y. et al. A game theoretical approach based bidding strategy optimization for power producers in power markets with renewable electricity. Energies, v. 10, n. 5, 2017.

XU, Y.; ZHANG, J. A two-layer two-stage dispatching strategy for active distribution network with micro-grid considering multiple interactions. Electric Power Systems Research, v. 187, p. 106504, 2020.

ZAREI, M.; SALAMI, A. Improving the game theoretic analysis of electricity auctions applied in medium markets. Journal of Computational Science, v. 17, p. 83 - 96, 2016.

Recebido em: 01/06/2021

Aprovado em: 20/06/2021

Publicado em: 30/06/2021 